The Division of Food Preservation has a total staff of 150 , of whom 78 are graduate research officers and experimental officers, and 49 are technical assistants. The field of research in which these workers are engaged is the handling, preservation, prosessing, storage and transport of meats, fish, eggs, fruits and vegetables. More than half the resources of the Division are devoted to fundamental research seeking a deeper understanding of the properties of foods and the changes which they undergo during processing and preservation. In addition, therefore, to technological projects on the preservation of foods by canning, dehydration, and refrigeration, the research programme includes many projects in the basic sciences.

Present chemical research is concerned with applications of gas chromatography to volatile constituents of foods, with anthocyanin and other flavonoid pigments in foods, and with reaction mechanisms in the non-enzymatic browning of foods and its control by sulphur dioxide. Workers in muscle biochemistry are elucidating the effects of rigor mortis and freezing on the protein and other constituents of muscle. Theoretical work on physics, on heat- and mass-transfer across laminar boundary layers, are related to many problems encountered by food technologists. Fundamental microbiological studies on the effects of water activity on microbial growth and on the germination and growth of bacterial spores are designed tu give precise information on factors governing the control of micro-organisms which cause food spoilage and food poisoning. Studies in plant physiology on the metabolism of carbohydrates and organic acids and on the properties of plant cell membranes are related to outstanding problems in the preservation of fruits and vegetables.

The new laboratories were officially opened on September 18 by Dr. D. A. Cameron, Federal Minister for Health and for the C.S.I.R.O., in the presence of a large gathering of representatives of Government and university departments and the Australian food industry. On the four days following, a Food Science Conference was held and was attended by 250 Australian food scientists and technologists and a few overseas visitors. The programme included symposia on "Chemical Aspects of Food Processing" led by Prof. C. O. Chichester of the University of California, Davis, on "Meat Quality" led by Dr. E. C. Bate-Smith, Low Temperature Research Station, Cambridge, and on "Food Preservation and the Organization of Plant and Animal Tissues" led by Dr. J. B. Biale, University of California, Los Angeles, and also panel discussions on public health aspects of handling and processing foods and on trends in food research.

\title{
UNCONVENTIONAL METHODS OF ENERGY CONVERSION
}

A JOINT session of Sections A (Mathematics and Physics) and $G$ (Engineering) of the British Association was held in Norwich to discuss the present situation with conventional methods of converting heat into electricity, the need for new methods, the principles of the new methods on which research is in progress, and the prospects for the future.

In the opening paper, Prof. T. G. Cowling (University of Leeds) pointed out first that with the established methods of using solar energy indirectly, by fossil fuel or by water-power, the proportion of the incident energy which is utilized for energy conversion is extremely small. This proportion is nevertheless, up to the present, readily available. The nuclear fission process is now well established, and can be controlled and made available satisfactorily. The direct employment of solar energy is, however, difficult because, although $1.5 \mathrm{~kW} . / \mathrm{m}^{2}$ arrives from the Sun outside the Earth's atmosphere, the problems of concentration mean that it is not readily available. Even greater difficulties with availability of the energy apply, of course, to thunderstorms, and so far to nuclear fusion processes. Thus, there are no new sources of energy likely to compete for some time with the existing sources. For new methods of utilizing existing sources of energy, those of interest appear to be thermoelectricity, the thermionic diode, magnetohydrodynamics and the fuel cell. The last of these was omitted from this session, and dealt with in a meeting of Section $G$ on the following day.

Mr. F. H. S. Brown (Central Electricity Generating Board), in the second paper, considered the incentives for establishing unconventional methods of energy conversion. The conversion of mechanical energy to electrical is now very efficient indeed, and the problem remaining with conventional methods is the conversion of heat to mechanical energy. This is, of course, limited ultimately by the efficiency of the Carnot cycle, though the best efficiency obtained is only about 70 per cent of this. To raise the efficiency of the Carnot cycle requires an increase in the temperature at which heat is fod into the cycle. With present materials, no engine with highly stressed moving parts can be operated continuously at a temperature much above $600^{\circ} \mathrm{C}$. Thus, although a fuel may be burned at $1,700^{\circ} \mathrm{C}$., no such temperature can be fed into an engine continuously. In the internal combustion engine, the explosion produces a high temperature which falls rapidly during adiabatic expansion, thus lowering the mean temperature of the engine parts. However, there is a limit in practice to the size of the internal combustion engine, it is expensive, and moreover, since it is of the reciprocating type, it suffers from friction, wear and noise to an unacceptable degree.

The steam cycle is thus more satisfactory, although it has a limiting temperature near $600^{\circ} \mathrm{C}$. The efficiency obtainable is about 40 per cent, and in this case, unlike the internal combustion engine, scaling up improves the performance obtainable. The gas turbine involves again continuous exposure to the maximum temperature, the limit of which at present is near $600^{\circ} \mathrm{C}$.; but a better performance can be obtained compared with the steam cycle because of the lower pressure and the larger heat rejection at the minimum temperature of the cycle.

It is clear that it would be very desirable to increase overall efficiency above 40 per cent, and the methods of achieving this could in principle be: (1) finding an intermittent process cheaper and more reliable than the internal combustion engine; (2) 
evolving better materials for use at high temperatures, for example, up to $1,700^{\circ} \mathrm{C}$.; (3) evolving a continuous method which does not stress working parts at high temperatures.

In the third paper, Dr. R. G. Siddall (University of Sheffield) described the work of Prof. M. W. Thring and himself on producing electricity directly from fast-moving plasmas. Here the ionized gas of the plasma replaces the conductor in a dynamo, and moves through a magnetic field, converting its kinetic energy directly into electricity. To obtain useful power, the plasma must have an electrical conductivity near $1 \mathrm{ohm}^{-1} \mathrm{~cm} \cdot \mathrm{.}^{-1}$, and it must move at several thousand miles per hour through a magnetic field of 10,000-20,000 cersteds. Moreover, the pathlength through this field to extract the energy must be many feet. Ordinary gases would have too low a conductivity at any feasible temperature, but by 'seeding' with a small proportion (say 1 per cent) of the vapour of an alkali metal, temperatures near $2,500^{\circ} \mathrm{C}$. would be sufficient. The simplest scheme would be to preheat air, compress it and mix with a fuel, burn it at about $2,500^{\circ} \mathrm{C}$., and expand through a nozzle to obtain the velocity. Unfortunately, this would cool the gas almost to $1,000^{\circ} \mathrm{C}$.; to maintain it near $2,500^{\circ} \mathrm{C}$. after expansion would need a combustion temperature near $6,000^{\circ} \mathrm{C}$. Thus, more sophisticated schemes are necessary.

Three ideas due to Prof. Thring are under investigation. First, continuous combustion at 2,500 $\mathrm{C}$. followed by expansion through a nozzle is used to produce the high velocity. Secondly, short bursts of preheated oxygen and fuel seeded with potassium are injected periodically into the combustion chamber immediately before the expansion nozzle. This burning gas is swept along in 'slabs' by the main gas stream. These slabs are expected to retain their initial temperature during their passage through the magnetic field. The second scheme involves obtaining the high velocity without pre-compressing and expanding. The combustion occurs at constant volume, in a chamber with inlet and exit valves which achieve pulsating combustion, so that again the hot gas passes in slabs through the magnetic field.

The third idea utilizes shock waves produced successively at the opposite ends of a tube, so driving a plasma to and fro through the magnetic field. This will generate power at each passage, and will produce alternating current. It is thought that these methods, if successful, will produce efficiencies of $50-60$ per cent.

Mr. P. Dunn (Atomic Energy Research Establishment) described, first, the basic principles of the thermionic diode as an energy converter, using the analogue of the steam boiler to illustrate the electron evaporation from the cathode and collection at the anode. He showed that for a given cathode operating temperature, the cathode work function should be below a maximum allowed value which is a function of the operating temperature, but that there is no optimum value. He indicated the importance of low anode work function, and of minimizing the effects of space charge either by using very close-spaced vacuum diodes or by positive ion neutralization of the space charge. The former method is impracticable for generation of Iarge amounts of power, though it is valuable for space vehicles. With cathodes operated at $1,400^{\circ} \mathrm{K}$., present diodes give an output of $0.7 \mathrm{~V}$., 1 amp. $/ \mathrm{cm} .{ }^{2}$, with an efficiency near 15 per cent. Higher outputs and efficiencies will be obtained with higher cathode temperatures. For use in a reactor, supposing that the fuel elements could be run at temperatures up to $2,000^{\circ}$ C., but not higher, a cathode with a work function less than $3 \mathrm{eV}$. would be required. This cannot be a metal, and none of the known oxides used as cathode materials is satisfactory at $2,000^{\circ} \mathrm{C}$. Uranium carbide has, however, a work function near $3 \mathrm{eV}$., and may be useful both as cathode material and, suitably enriched, as the fuel element. Using cæsium vapour to give the positive ions, this should maintain a cresium coverage on the anode which would give a reasonably low anode work function. It is not certain yet whether the cæsium would be adequately ionized in such a diode, and it is known that there are considerable difficulties in using cæesium due to attack of other metals, glass and ceramics. Thus other forms of ion injection are under investigation.

The thermionic diode is conveniently used with fission nuclear power, as it is easy to obtain the required heat flux to the cathodes. To produce a plasma jet would not be easy with a reactor. Conversely, with fossil fuel, it is not difficult to produce such a jet, but the heat flux to a cathode is difficult to obtain. The thermionic diode is suitable for 'topping', in that the heat injected at the cathode at $2,000^{\circ} \mathrm{C}$. is conveniently rejected at the anode at temperatures of $400-600^{\circ} \mathrm{C}$., so that it could then be used in a conventional steam cycle. The thermionic diode therefore promises a useful step forward under the third heading above. Incidentally, the highvelocity plasma cannot be used after the hottest part of the gas has cooled below about $2,000^{\circ} \mathrm{C}$., so that this method could also be used for topping.

In the final paper, Prof. D. A. Wright (University of Durham) discussed thermoelectricity as a means of generating power directly from heat. He first outlined the basic principles, showed why the performance of metallie thermojunctions was poor, and contrasted the possibilities with semiconductors. With the latter there are many complications, but the main requirements with the 'broad-band' type are that they should have a sufficiently high energy gap, depending on the required temperature of operation; that it should be possible to prepare them $n$-type or $p$-type, with a Seebeck coefficient $\alpha$ near $\pm 200 \mu \mathrm{V}$./deg. C.; and that they should then have a high electrical conductivity $\sigma$ and a low thermal conductivity $K$. The usefulness of material is, in fact, determined by the quantity $z T$, where $z=\alpha^{2} \sigma / K$ and $T$ is the absolute temperature. It would be necessary to prepare the material reliably and repeatably, reasonably cheaply, with a high degree of uniformity of properties over every sample, from sample to sample, and from batch to batch. It must be possible to make low-resistance reliable contacts, and the material must not melt or decompose in operation; the deliberately added impurities must not diffuse out, and impurities from the contacts or from the environment must not diffuse in.

One of the best materials so far is bismuthantimony-telluride, which has a value of $z T$ slightly greater than unity, but cannot be operated above $150^{\circ} \mathrm{C}$., because of its low-energy gap. With the hot junction at $150^{\circ} \mathrm{C}$., cold junction at $0^{\circ} \mathrm{C}$., a thermojunction between $p$ - and $n$-type material would give a junction efficiency near 7 per cent. Lead telluride can be operated at $500^{\circ} \mathrm{C}$., but with $z T$ less than unity, so that the junction efficiency between $500^{\circ} \mathrm{C}$. and $0^{\circ} \mathrm{C}$. is about 12 per cent. Unfortunately, the figures realizable in practice are lower than these because of resistance at contacts, temperature drop 
at contacts, and, with fossil fuels, problems of heat transfer to the hot junctions following combustion.

Progress in finding materials which can be operated at higher temperatures is slow because there are incompatibilities in the requirements. To obtain higher energy gaps and so permit higher operating temperatures one needs compounds of lower atomic weight which, compared with bismuth and lead tellurides, tend to have higher thermal conductivities and lower values of the electrical conductivity for a given Seebeck coefficient. Thus the trend is for materials which can be operated at higher temperatures $T$ to have lower values of $z$, and in fact $z T$, than materials which can be operated only at low temperatures. Indium arsenide containing gallium or phosphorus can be operated to about $700^{\circ} \mathrm{C}$., but $z T$ is only about $0 \cdot 5$. More promising are some compounds such as $\mathrm{AgSbTe}_{2}$ and its analogues formed by cross-substitution from the same columns of the Periodic Table. These have lower thermal conductivity than their mean atomic weight would predict. Values of $z T$ as high as 1.5 up to $700^{\circ}$ or $800^{\circ} \mathrm{C}$. seem likely to be attained with these compounds. Materials which could be operated to $1,100^{\circ}$ or $1,200^{\circ} \mathrm{C}$. have so far lower values; for example, cerium sulphide, $z T$ near 0.5 , and nickel oxide, $z T$ still lower. Thus the highest junction efficiency which is theoretically obtainable at present between. $1,200^{\circ} \mathrm{C}$. and $0^{\circ} \mathrm{C}$. is about 17 per cent, while the best actually obtained so far for this range is only about 6 per cent. This is in a 'eascaded' system in which three or four stages are used, the heat from the first stage passing to the second and so on, and different materials being used in the different stages, to match the temperature involved.

To obtain useful performance for 'topping' in power generation, values of $z T$ near unity would be necessary at temperatures up to $1,600^{\circ} \mathrm{C}$., while for direct replacement of present generators operating up to $600^{\circ} \mathrm{C}$., values of $z T$ would have to exceed 4 . There seems little prospect at present of obtaining values as high as this in either temperature-range. Meanwhile, research is continuing, and this type of generator is useful in spite of low efficiency for the production of low power in portable equipment and in remote situations where such a generator has to run unattended for long periods.

\section{THE INTERNATIONAL COUNCIL OF SCIENTIFIC UNIONS}

\begin{abstract}
HE ninth assembly of the International Council of Scientific Unions (ICSU) met in London during September 25-28 under the auspices of the Royal Society. About 130 delegates attended, each representing a particular scientific discipline or organization. They came from all continents, and all, to quote Prof. A. V. Hill, were working scientists of the world. If the Council were a political union, it might be better known. In his welcoming address Sir Howard Florey described it as a living example of voluntary international co-operation by scientific men themselves in the best use of science to serve a world community, and in educating the public about the real purpose of scientific knowledge and research. Many changes in the modern world, although often described as social or economic, may stem more directly from the growth and applications of science itself. To say, however, that science has now become so big that it is a matter for Governments alone is a dangerous half-truth, for freedom of thought and objective analysis are essentials which must be preserved, unencumbered by an excessive bureaucracy or by considerations of political expediency. The principles and aims of science are not national but universal. International co-operation is no longer just a matter of nomenclature, symbols or standards; we have reached a stage when measure. ments on a particular phenomenon may be useless unless made simultaneously at widely separated places. We must also consider, for example, the effects of space research or of nuclear explosions not only on the future progress of scientific research on the cosmos itself but even more specifically on the world as a place for humanity or any other biotic community. No observer at this assembly could fail to sense in this distinguished gathering an underlying realization of responsibility by scientists themselves of all lands, to apply their knowledge and such influence as they may possess for the benefit of all mankind.
\end{abstract}

The International Council of Scientific Unions was established in 1931. Its precursor, the International Research Council, had been set, up in 1919 but proved unsatisfactory because it was restrictive, in no sense fully international, and because it allowed feelings engendered by the First World War to cloud its proper function. These mistakes were avoided after the Second World War, and the recent assembly reaffirmed its previously declared non-political philo. sophy by admitting to membership under the terms of its rules Hungary (Academy of Sciences), North Korea (Academy of Science, Phyongyang), South Korea (Academy of Science, Seoul), Ghana (Academy of Learning), Ceylon (Association for the Advancement of Science), and East Germany (Berlin Academy of Sciences).

The Council has several objects. It aims to coordinate the activities of the international scientific unions, and to be a co-ordinating centre also for the national organizations which are in membership. It seeks to encourage soientific activity in fields which do not fall directly within the scope of any existing organization, to enter through the national organizations into relations with Governments and to maintain relations with the United Nations and its Specialized Agencies. The Council consists of national members and scientific members. There are now fifty-one national members, each representing the authoritative scientific organization in the country concerned-an academy, national research council or similar institution or, in a very fow cases where no appropriate body exists, the Government itself. Fourteen inter. national unions are now members. Of these, the general unions include astronomy (IAU), biology (IUBS), pure and applied chemistry (IUPAC), geodesy and geophysics (IUGG), geography (IGU), pure and applied physics (IUPAP), mathematics (IMU), and geology (IUGS), which was admitted at the recent Assembly. The specialized unions include crystallography (IUCr), history and philosophy of 